\title{
HOR CHA'AN: LA SERPIENTE MÍTICA CH'O ORTÍ EN EL ARTE Rupestre De Chiquimula, Guatemala
}

\author{
Carlos Alberto Batres Alfaro \\ Ramiro Edmundo Martínez Lemus \\ Lucrecia Dalila Pérez García
}

Resumen. El grupo cultural ch'orti', de la familia lingüística mayanse ch'ol, ha quedado aislado del resto de comunidades mayas de Guatemala, lo que indica que la tradición oral ha recibido poca influencia externa. Desde la cosmovisión ch'orti', el paisaje-montañas, abrigos rocosos y cuevas-se relaciona con movimientos de serpientes míticas (chicchan) que habitan el subsuelo y fuentes de agua. Hay una serpiente mayor llamada Hor chan, considerada como provedora de la lluvia y la fecundidad para la humanidad. Las fuentes etnohistóricas del Posclásico, el análisis simbólico y lingüístico, la etnografía y el uso de la metáfora ayudan a sustentar la creencia de origen prehispánico en una deidad-serpiente que mantiene la continuidad de la vida y la fertilidad de la tierra.

Palabras clave: ch'orti', serpiente, arte rupestre, chan, chicchan, Hor chan, fertilidad, agua, padrino.

Carlos Batres, maestro en Antropología, proyecto Chiquimula, Universidad de San Carlos de Guatemala. Temas de especialización: arte rupestre, etnografía ch'orti', lingüística maya, antropología, sistemas de información geográfica. Correo electrónico: cbatres@siu.edu.

Ramiro Martínez, licenciado en Arqueología, Universidad de San Carlos de Guatemala, Fundación de Antropología Forense de Guatemala. Temas de especialización: arte rupestre, etnografía ch'orti' , antropología forense. Correo electrónico: raedmale@hotmail.com.

Lucrecia Pérez, licenciada en Arqueología, Universidad de San Carlos de Guatemala, proyecto Chiquimula/Grupo Guatemalteco de Investigación de Arte Rupestre, Universidad de San Carlos de Guatemala. Temas de especialización: arte rupestre, etnografía ch'orti', medicina y plantas medicinales prehispánicas. Correo electrónico: luckybatres@gmail.com.
Abstract: Ch'orti' cultural group (from the linguistic Mayan Cho'lfamily) has been isolated from the other Guatemalan Maya communities; it indicates that the oral tradition has received little external influence. Landscape (mountains, rock shelters and caves), exerts influence over ch'orti' cosmovision, because it relates to movements of mythical serpents (chicchan) that inhabit the underground and water sources. There is a major serpent, called Hor chan, which provides rain and fertility to humanity. Ethnohistorical sources from Postclassic, symbolic and linguistic analysis, ethnography and use of metaphor, help to sustain the preHispanic belief in a serpent-deity, which maintains the continuity of life and land fertility.

Keywords: ch'orti', snake, rock art, chan, chicchan, Hor chan, fertility, water, godfather

Enviado a dictamen: 20 de abril de 2009

Aprobación: 28 de mayo de 2009

Revisiones: 1

\section{Introducción}

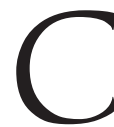
h'ortí es un grupo o comunidad lingüística que forma parte de la cultura maya. Actualmente se localizan en el extremo central-oriental de la república de Guatemala, sobre la frontera con Honduras. Su cosmovisión, creencias $\mathrm{y}$ tradiciones fueron estudiadas a inicios del siglo XX por el arqueólogo Charles Wisdom de la Universidad 
de Chicago. Más tarde, a mediados de siglo, Rafael Girard, investigó nuevamente el mismo tema y añadió a su trabajo etnográfico varias aproximaciones arqueológicas interesantes. Sólo a finales de siglo se repite el interés en la zona por dos equipos que trabajan de manera separada. El primero se trató de un grupo de antropólogos liderados por Brent Metz (Universidad de Kansas) y Julián López (Universidad de Córdoba); el segundo, de un equipo de arqueólogos de la Universidad de San Carlos de Guatemala, que por primera vez estudió el arte rupestre de la zona.

En el presente artículo se explora la idea de que una pintura rupestre, del sitio conocido como peñasco Los Migueles, representa a la mítica serpiente llamada Hor chan: ser sobrenatural que, según la creencia de la etnia ch'ortí, regula la abundancia o carencia del agua en la zona y los deslizamientos o movimientos telúricos.

Para analizar el problema, en esta investigación se hizo uso de la aproximación etnohistórica referente al período Posclásico, del análisis simbólico y lingüístico, la etnografía y la metáfora. Entendida como un símbolo, esta pintura rupestre connota un ser esencialmente natural con capacidades sobrenaturales. Sin embargo, sus facultades benéficas sólo pueden ser puestas a disposición de la humanidad mediante la petición ejercida por un sacerdote, chamán o padrino, quien lleva a cabo un ritual de ofrecimiento y sacrificio en lo alto de cerros, previo a la llegada de las lluvias.

El paisaje ejerce una fuerte influencia en la cosmovisión ch'orti'. Marcada por una falla geológica, la geografía de esta zona está definida por montañas escarpadas, formaciones rocosas de cierta altura, abrigos rocosos, cuevas, depresiones y valles rectos y angostos. Dado que el paisaje no es estático, los ch'orti' refieren que los derrumbes, deslaves y hundimientos son el producto de serpientes que se mueven dentro de la tierra y en los cerros. No obstante, hay también otra serpiente más importante que habita en un plano sobrenatural y a quien se asigna la potes- tad de manejar el agua y mantener la vida. Algunas fuentes etnohistóricas del Posclásico corroboran la idea de serpientes como responsables del acarreo de la lluvia. Un análisis practicado a ciertas expresiones lingüísticas indica que en el idioma ch'orti' es bastante común el uso de términos relacionados con la palabra chan que significa serpiente, movimiento, contracción. Hor chan es el nombre que los ancianos entrevistados utilizan todavía para referirse a la gran serpiente mítica, quien a su vez se transforma en una metáfora del paisaje, de las fuentes de agua, la fertilidad y los movimientos de la tierra.

\section{El análisis del contexto y los símbolos. La impor- tancia del aporte etnográfico.}

\section{Paisaje}

El paisaje se entiende como la integración de los fenómenos naturales y humanos en el espacio circundante. Más que para admirase, el paisaje natural es un sistema íntimamente relacionado con la vida humana. Desde esta perspectiva, el paisaje se convierte en un elemento simbólico que adquiere significado cultural, utilizado para comunicar, crear y recrear patrones de identidad y sociabilidad (Rapoport, 1992). Así, el paisaje es una matriz para expresar quien o quienes hacen algo, donde, como y porqué.

Algunos investigadores (Bradley, 1997; Whitley, 1998) han interpretado el paisaje y la distribución del arte rupestre no sólo como las características de una orografía particular (escala local), sino también como redes simbólicas (tipo y estilos de arte rupestre) que identifican la diversidad cultural de los grupos sociales que se extienden (escala regional) a través del paisaje. El análisis del paisaje, la localidad, la frecuencia y el estilo permiten estudiar cómo el arte rupestre se transforma en un elemento cargado de simbolismo particular o general, portador de identidad cultural. 


\section{El arte cultural}

Alcina Franch propone que se identifique al arte (rupestre) "como un lenguaje" mediante el cual se da la siguiente interacción (Alcina, 1982: 237):

1. Quien lo produjo se comunica con su grupo cultural.

2. El grupo cultural le da existencia y le proporciona inagotable capacidad creadora.

Por ello, el arte puede ser considerado como un sistema de signos, codificados y socializados —en menor o mayor grado-, mediante el cual la sociedad recibe informaciones con valor referencial. Al ser estos signos el mensaje mismo, transmiten conceptos conocidos o sobrenaturales. Cabe afirmar que como código artístico, el arte rupestre tiene carácter polisémico, lo que implica que un significante ${ }^{l}$ puede remitir a varios significados ${ }^{2}$ y cada significado puede expresarse por medio de varios significantes. Esto se debe a que la representación rupestre es en realidad un agregado de códigos superpuestos, hecho por un especialista quien "tuvo la capacidad de elegir entre varias posibilidades de formular un mensaje" (Alcina, 1982: 241).

\section{Los símbolos}

El análisis de los símbolos dentro de su propio contexto cultural es importante porque estos son medios culturales usados para caracterizar acciones o representar hechos entre el individuo o individuos y su medio circundante (Geertz, 1973: 141).

Para Geertz (1973), los símbolos no son solamente expresiones que encapsulan la realidad social y psicológica del hombre, sino que le ayudan a conceptualizar esa realidad. Adicionalmente, los símbolos son elementos importantes para unir. En los rituales, por ejemplo, los símbolos son conectores sagrados que fusionan el tiempo mundano con el tiempo religioso; una transpo- sición que adquiere valor real y sintetiza la visión del mundo $\mathrm{y}$ su ethos.

\section{Análisis simbólico y análisis etnográfico}

En muchas de las investigaciones de arte rupestre realizadas en los últimos veinte año, se han hecho comparaciones de información etnohistórica, etnográfica y arqueológica, que permiten sustentar que el arte rupestre puede tener tres fuentes de origen: 1) naturalista, que incluye elementos del entorno, 2) familiar o similar, que implica la representación de rituales de paso u otras ceremonias no rituales y 3 ) ritual, que incluye la presencia de un chamán, como generador de las representaciones rupestres. A este respecto se entiende que mientras el ritual es colectivo, la representación rupestre es individual, dado que todo un grupo podría participar de una ceremonia, pero no todo el grupo pintó sobre la superficie rocosa elementos con contenido ritual. Quien pintó habría de ser el especialista ritual. En el caso de las categorías 1 y 2, las representaciones rupestres pueden no ser de uso público ni necesitar de un especialista para producirlas, aunque hayan sido producidas en conjunto por un grupo reducido (Viramontes, 1999: 84, 86).

Whitley proporciona varios métodos para interpretar el arte rupestre. Importantes para el caso de la región ch'orti' son los análisis simbólico y etnográfico. El análisis simbólico establece que se debe entender tanto el significado de las pictografías, como del sitio rupestre, ya que este no es un escenario neutral. Para un chamán, el motivo rupestre puede ser la representación de un ser espiritual, pero el sitio es el portal hacia lo sobrenatural habitado por espíritus de animales, pero no por actores míticos (Whitley, 2005: 83).

Este contexto asociativo - motivos rupestres en un sitio con su propio significado simbólico- ayuda a aclarar el significado específico del conjunto, entendido de esta forma particular: los actores míticos y grupos parcializados no están asociados con lo sobrenatural, 
mientras que los espíritus auxiliares y otro tipo de seres anímicos, están estrechamente conectados a ese reino (Whitley, 2005: 83).

Otra característica de los sistemas simbólicos se refiere a la metáfora que enfatiza similitudes entre el significante y el significado, de tal manera que poseen propiedades comunes que permiten asimilarse: si la relación es muy estrecha, el significante se convierte en una representación del significado. Se ha demostrado que la metáfora es uno de los bloques constructivos del simbolismo lingüístico y esto es muy importante en el caso del arte rupestre, sobre todo cuando éste se deriva de experiencias producidas por estados alterados de conciencia que son intrínsecamente difíciles de describir (Alcina, 1982: 240-241, Whitley, 2005: 85). Así, las metáforas originadas en las alucinaciones corporales de trance son una forma de describir experiencias sobrenaturales. Las más comunes de estas metáforas de trance son: muerte, agresión o lucha, vuelo, nadar o ahogarse, excitación sexual y transformación corporal. El origen de estas metáforas está en las funciones propias del cuerpo humano y no en creencias culturales específicas, lo que enfatiza que mucho del simbolismo es sistemático, lógico y comprensible y no arbitrario u oscuro (Whitley, 2005: 85).

El análisis etnográfico ha aportado grandes avances en la investigación de arte rupestre (Meg Conkey, 1997, citada por Whitley, 2005: 85), ya que proporciona información sobre los orígenes y significado histórico del arte rupestre como un corpus. En este sentido, el análisis etnográfico no está destinado al estudio de casos particulares, sino que toma al arte rupestre como un elemento que está inmerso en el complejo cultural de un grupo. De esta manera se adquiere una perspectiva general de cómo y por qué se produjo arte rupestre, y se asignan expectativas (o modelos) sobre los motivos que llevaron a su realización y del significado del mismo dentro de su propia esfera cultural (Whitley, 2005: 85-86).
Por lo tanto, la importancia de estudiar la etnografía del arte rupestre tiene dos objetivos: ofrecer un contexto en el que puede estimarse la verosimilitud de una determinada interpretación; y proporcionar una serie de hipótesis competitivas que puedan ser evaluadas para cualquier caso de estudio. No hay ninguna razón para suponer que cada caso necesariamente se ajustará al "origen y significado" proporcionado por la etnografía; por el contrario, un punto de partida para el análisis es asumir que un caso particular estará razonablemente cercano a la gama de variación etnográfica conocida. Por otra parte, si el origen y significado de un caso es significativamente divergente de la etnografía conocida, entonces debe demostrarse cómo difiere, por qué las diferencias son relevantes y de que manera esta evidencia apoya una interpretación potencialmente excepcional (Whitley, 2005: 86).

Un punto importante del análisis etnográfico es que para llegar a la interpretación se requieren varias líneas de evidencia y diferentes tipos de confirmación independiente. Las líneas de evidencia (soporte) de la investigación etnográfica son múltiples informantes (e idealmente, distintos etnógrafos), mientras que las diferentes formas de confirmación pueden incluir comunicaciones orales directas, alusiones metafóricas, términos lingüístico o idiomáticos y nombres de lugares (Whitley, 2005: 89).

\section{Icono e identidad}

Eco (1976: 57) afirma que "un ícono es un signo que hace referencia a su objeto, en virtud de una semejanza de sus propiedades intrínsecas, que de alguna manera corresponden a las propiedades del objeto, o bien a un signo basado en modalidades particulares de producción". Para López (1994: 36), la función esencial del icono no radica en establecer en el mismo todas las características que denota el objeto referido, sino más bien algunas de ellas capaces de esbozar al objeto, para posteriormente analizar y comprender el mensaje implícito. Estas características esbozadas pueden ser elementos que le 
otorgan identidad (atributos, actitudes y pautas que permiten la inclusión) dentro de un grupo cultural.

Un ejemplo del uso de la serpiente como icono de distinción étnica ${ }^{4}$ es descrito por Rice en la región de los lagos de Petén central. Rice propone que las particularidades de los estilos serpentinos en la iconografía cerámica de la zona, son usadas con dos propósitos: como indicadores sociales de grupo y de etnicidad al interior de la misma; y como indicador de la participación de la zona de Petén central, en el sistema regional de culto a la serpiente (Rice, 1983: 875).

\section{La serpiente en el período Postclásico}

En el período Postclásico, kan y coatl son los términos genéricos utilizados en maya yucateco y náhuatl para nombrar a las serpientes. Estos nombres se combinan con otros términos para designar a especies particulares o bien para dotarlas de simbolismo. En los calendarios de estas culturas, el quinto día se denomina chikchan o coatl, respectivamente. Pero como todo lo sobrenatural en las culturas prehispánicas, la serpiente también está dotada de dualidad. Por una parte era de buena fortuna para los que nacían en el día serpiente, pues se creía que vivirían prósperos y felices. También era propicia para los mercaderes quienes sólo partían a sus largas jornadas en este día. Sin embargo, si se cruzaba ante un caminante consideraban que era de mal augurio ya que significaba que le había cortado el hilo de su vida y podía morir pronto. Un mercader que no hacía sacrificios y ofrendas a la serpiente en su día, podía implicarle la pérdida de sus negocios. Finalmente, las serpientes proveían de alimento, proporcionaban su piel y se empleaban como medicamento para curar enfermedades de la piel, circulatorias, inflamaciones y otras más severas (Aguilera, 1985: 73-74).

Durante el mismo período, Pérez-Castro (1996: 4) relaciona a la serpiente, en una línea naturalista, con ritos de fertilidad, con el agua y el fuego. Sin embargo, también le da un significado espiritual, la vincula con la sabiduría y por extensión con Quetzalcoatl o Kukulkan, la deidad que enseñó a la humanidad, que le dio vida, el saber y la destreza. Según Rice (Rice, 1983), la serpiente es la representación más común como deidad, en su advocación de Serpiente Emplumada. Incorporada a casi cualquier material cultural, su significado se puede definir de acuerdo al contexto arqueológico y el estilo iconográfico; sus representaciones variarán según los sutiles cambios que presenten los motivos plasmados (colores, orientación y composiciones en las que se encuentre, ya sea en conjunto o de manera individual). La serpiente se ha utilizado para simbolizar parte del cuerpo humano, la tierra, el cielo, el mundo, enfermedades, fecundidad, esperanza, muerte, agua, germinación, maíz y fuego (Gamboa, 1996: 5; Pérez-Castro, 1996: 4).

Entre las deidades, Huitzilopochtli es una de las que porta insignias de serpiente, ya que en la mano lleva un reptil de fuego o turquesa. Otras deidades del panteón náhuatl cuyo nombre se asocia a la serpiente, son Xiuhcóatl, que simboliza el calor, el fuego y la luz; Cihuacóatl o mujer de la culebra, diosa de las cosas adversas, como pobreza, abatimiento y trabajos; Chicomecóatl, deidad de los alimentos y mantenimientos; Mixcoátl, dios de las tempestades y la caza; Coátlicue, madre de los dioses, diosa de la medicina; y, por supuesto, Quetzalcoátl, dios de los vientos, quien barría el camino a los dioses del agua para que trajese el agua (Aguilera, 1985: 73; Sahagún, 2006: 30-32).

\section{Descripción del área ch'orti'}

\section{Localización geográfica}

La etnia ch'orti' se encuentra localizada en la sección central del oriente de Guatemala, principalmente en el departamento de Chiquimula y en parte del de Zacapa, hacia la frontera con la República de Honduras y por tanto, cercano al antiguo centro prehispánico de Copán. A esta zona se le denomina recientemente, "Cuenca Copán Ch'orti”. Ésta inicia en el extremo 
fronterizo y cubre todos los territorios ubicados a lo largo del recorrido del río Grande/Camotán/Carcar (nombres que toma el río Copán del lado guatemalteco), en los municipios de Camotán, Jocotán y San Juan Ermita, hasta el punto donde éste se une con el río Zacapa, en el municipio de Chiquimula.

El paisaje de la cuenca está definido por una falla geológica (falla de Jocotán), que ha formado abundantes cerros, montañas, hundimientos, paredones y abrigos rocosos, así como fértiles valles que se caracterizan por ser alargados, estrechos y surcados por ríos, donde se cultiva maíz, frijol, cebolla, berenjena, tomate, pimientos y otras legumbres. El resto del paisaje está cubierto por chaparros y espinos.

\section{Idioma}

Cultural y lingüísticamente, los ch'orti' están emparentados con los chontales de Tabasco y con los choles de Chiapas. El idioma ch'orti' pertenece a la familia lingüística mayanse ch'ol y se separó de otros idiomas del grupo alrededor del 600 d.C., momento en el que se trasladó al este, al área cercana al actual sitio de Copán. Sobre el grupo ch'ol se han hecho dos propuestas interesantes. La primera es que durante el período Clásico se hablaban idiomas del mismo grupo lingüístico en todas las ciudades del sur de Mesoamérica, desde Palenque hasta Copán; la segunda es que en dicho período, Petén fue habitado por hablantes de chól, aunque no se sabe que tan al norte llegaría esta ubicación (England -basado en Kaufmann, 1974-, 1999: 643-644).

En época prehispánica, el ch'orti' se ubicaba en la parte oriente de la actual república de Guatemala (Chiquimula), el occidente de Honduras y aún una parte del noreste de El Salvador. En la actualidad, en Guatemala los hablantes de ch'orti' residen solamente en ciertas áreas dentro del departamento de Chiquimula, especialmente en los municipios de Jocotán, Camotán, Olopa, Quezaltepeque, San Jacinto y San
Juan Ermita; asimismo en el municipio de La Unión, departamento de Zacapa. En Honduras el ch'orti' se considera lengua muerta, aunque en las comunidades de El Paraíso, Carrizalón y Ostuman hay ancianos que todavía hablan Tcor ti, que en español puede traducirse como ch'orti'.

\section{Etnicidad}

En nuestros días, la etnia ch'orti' está formada por personas muy pobres que se mantienen de sus siembras y las ventas de algunas artesanías fabricadas con tule (junco), lazo, palma, jícaras, jarcia y con otras plantas que crecen en la región. Los ch'orti' han sido relegados a la parte alta de los cerros donde las tierras son poco fértiles, condición que limita su calidad de vida. Viven en ranchos de bajareque con paredes y techo forrados con hojas de palma. Visten los hombres calzón y camisa hechos con manta blanca (traje que se ha perdido en un 90\%), usan sombrero de palma y normalmente se acompañan de un morral tejido con lazo y llevan machete corvo, como parte del atuendo. Las mujeres, en cambio, visten un vistoso y colorido traje, complementado con abundantes vuelos, ribetes y encajes. Los menos elaborados están hechos con telas brillantes (seda, satín), decorados con alforzas y pocos encajes. Se adornan el cabello con ganchos metálicos y llevan al cuello collares que se entretejen para nunca quitárselos. Los hombres como las mujeres calzan sandalias de pitas de cuero y suela de caucho o, bien, utilizan zapatos plásticos.

\section{Sitio Peñasco Los Migueles y la representación rupestre de la serpiente}

\section{Descripción de los sitios rupestre de la región ch'orti'}

Chiquimula es uno de los muchos departamentos de Guatemala que cuenta con sitios arqueológicos con manifestaciones gráfico-rupestres. Destaca porque hasta el momento se han registrado catorce sitios (abrigos 
rocosos y una cueva de origen calizo), en cuyas paredes se realizaron una serie de paneles que reflejan a través de asociaciones de dibujos, pinturas o tallas, la naturaleza y el sistema de creencias de sus creadores. Los sitios son conocidos como Chatún de la Rebalsa, Peñasco Los Migueles, Peñasco Alonzo, Peña de las Campanas, Peña Pequeña, Peña del Divisadero, Peña Pintada, Peñasco Cerón, Cueva de Jocote, Peñasco El Limón, Fierros del Duende, Peña de la Hierba Buena, Peña del Diablo y Peña Pintada de Ipala ${ }^{5}$, y se localizan en los municipios de Camotán, San Juan Ermita, Chiquimula, San Jacinto, Quezaltepeque, Esquipulas e Ipala.

Las representaciones rupestres de toda la zona pueden agruparse en cinco categorías: antropomorfas, zoomorfas, fitomorfas, astromorfas y abstractas o geométricas. En la primera categoría se encuentran las figuras que pertenecen a rasgos humanos (manos, rostros y figuras, solos o asociados en escenas). El segundo grupo lo conforman imágenes de animales (aves, serpientes, tortugas, lagartijas, felinos, entre otros). Los fitomorfos son gráficos en los que se trazaron elementos del reino vegetal; a éstos siguen los astromorfos (representaciones de soles, estrellas y puntos distribuidos de manera que semejan constelaciones); y, finalmente, las figuras abstractas o geométricas son trazos simplificados que no se asocian a formas naturales concretas. También se pueden describir manchas amorfas y otros restos de pintura que originalmente debieron tener alguna forma específica pero que con el paso del tiempo se fueron deteriorando por efectos de agentes climáticos o por acciones de vandalismo humano.

\section{El sistema de abrigos rocosos de San Juan Ermita}

Los abrigos rocosos de San Juan Ermita se ubican en las montañas, alrededor de los $1000 \mathrm{~m}$ SNM. Son formaciones de caliza, algunas de las cuales son de gran tamaño y a las que los arqueólogos y vecinos dan diferentes nomenclaturas para su identificación (peñasco Los Migueles, peñasco Alonzo, peña de las Campanas, peña
Pintada, peña del Devisadero, peña Partida, entre otros). El conjunto rocoso cubre un radio de $150 \mathrm{~m}$ en el espacio de las aldeas Buena Vista y Minas Abajo.

Aunque los lugareños siempre han mantenido relación con "las peñas pintadas (rupestres)", fue hasta en el año de 1996 cuando se estudian por primera vez por la Universidad de San Carlos de Guatemala. Esta institución llevó a cabo la documentación fotográfica y el registro de los motivos, levantamiento topográfico de los sitios, hizo reproducciones a escala y excavaciones cuando fue factible (solamente en los peñascos Los Migueles y Alonzo). En la base de los mismos y en los alrededores es importante la riqueza de cuarzo, grafito, mica y otros tipos de rocas y minerales.

\section{Sitio Peñasco Los Migueles y la representación rupestre de la serpiente}

Peñasco Los Migueles, también conocido por los vecinos de las inmediaciones como Peña Pintada, se localiza en el caserío Peñascos de San Juan Ermita. Es un abrigo rocoso de caliza gris que mide aproximadamente $100 \mathrm{~m}$ de alto por $70 \mathrm{~m}$ de ancho. En esta peña la representación rupestre predominante es una serpiente de $5.25 \mathrm{~m}$ de largo ${ }^{6}$, cuyo cuerpo está formado por 14 almenas dobles, originalmente pintadas de negro y rojo, pero que ahora ha perdido casi la totalidad de su trazo (Batres, 1999). La representación está plasmada con orientación EsteOeste $^{7}$ y claramente posee las fauces abiertas y cuernos en la cabeza. Esta pintura es altamente significativa para la región ch'orti' porque los reptiles se asocian con el recurso hídrico y los movimientos telúricos.

Otras representaciones propuestas como importantes en el arte rupestre de los ch'orti' son las espirales, las cuales se ha interpretado como el viento. Para los padrinos encargados de los rituales ch'orti', el viento está relacionado con la lluvia, pues es quien la lleva por toda la tierra. Es por ello que las representaciones de espirales pudieran también representar serpientes enroscadas. 
El área geográfica donde se ubica este sitio es parte de la falla geológica de Jocotán, por lo que la actividad sísmica es frecuente. En la cosmovisión ch'orti', los sismos son el resultado del desplazamiento de una serpiente mítica que habita en el subsuelo. La forma de los montes y montañas que componen el paisaje de la región ch'orti' son también el resultado de los movimientos de este ofidio. Por otra parte, la presencia de lluvia, de inundaciones, el flujo de los ríos y la presencia de otras fuentes de agua también se deben, desde estas concepciones, a la serpiente mítica que habita los cielos y los cursos acuosos.

Nomenclatura y etimología de la serpiente de la región ch'orti'

La serpiente mítica de la región ch'orti' , con su dualidad benéfica-maléfica, es conocida con el nombre propio de Hor Chan y genéricamente como chicchan o chijchan (también en maya-yucateco). Al respecto, el Diccionario abreviado Maya Ch'orti' (Hull, 2005), señala que chijchan es sierpe o serpiente mitológica, una serpiente mitológica con cuernos; chan, es también serpiente, culebra, calambre simple. El Diccionario Chorti (Wisdom, 1950), es muy amplio en cuanto definiciones del término y de éste asociado a otros caracteres o usos de la serpiente. Wisdom, determinó los siguientes:

chan: serpiente, gusano largo (genérico), intestino, barriga, línea en zigzag, camino sinuoso, estancando, espasmo muscular, cólico

ch'i'ih chan [chan: serpiente] chicchan: deidad de la lluvia y espíritu del agua, también llamada ah ch'i'hchan and ch'i'hchan noh ha'

ch'i'ih chan ik'ar ch'i'ij chanikar [ikar: viento]: tormenta, huracán (se dice que es causado por el paso de un chicchan)

ch'i'ihchan ixik [ixik: mujer]: aspecto femenino de Chicchan'

ch'ur i's ch'a'n: nombre de una cerro cercano a Camotán, en el cual se dice que vive un chicchan (su rol es el de protector del pueblo y municipio de Camotán).

ha' chan: cualquier serpiente acuática

haha' chan: cualquier serpiente acuática

hor cha'an: padrino (horchán)

mak chan: arcoiris

noh chan [noh chan] 'Chicchan: deidad-serpiente del agua y la lluvia; boa.

noh cha'an: ceremonia importante, ceremonia para "hacer llover"

noh chan chicchan: deidad-serpiente de la lluvia, boa.

Fuera del área ch'orti', pero haciendo referencia al mismo término, el Diccionario K' iché-Inglés (Christenson, 1985), indica que kumatz (n) es serpiente, enfermedad de serpiente (calambre repentino recurrente y articulaciones dolorosas), punzada.

Simbolismo de la serpiente en la cosmovisión y rituales ch'orti'

Parte de la vida religiosa e ideológica de los ch'orti' está impreganada de creencias en seres sobrenaturales que incluyen animales, cruces y otros elementos que habitan tanto en la tierra como en el cielo.

En la mitología y la religión de los grupos culturales aborígenes de Mesoamérica reaparece el tema de las serpientes, por lo que se puede deducir que el culto a este animal tuvo una gran importancia en las prácticas antiguas de esta región: este ser mítico estuvo dotado de vida propia en las tradiciones de esta área y continua estándolo.

En la región ch'orti' de Chiquimula, las tradiciones orales hablan de una serpiente mítica que tiene contacto con los dioses y que puede enviar la lluvia a los moradores de la tierra. Es de esta forma que las cosechas pueden fructificar. Trae tanto bendiciones (lluvia), como desgracias: sequías — estación seca一, deslaves, inundaciones, hundimientos en el suelo y otras.

Entre la fauna mitológica ch'ortí', según Wisdom (1961: 447, 463) ${ }^{8}$, había animales fantásticos o divinos a

8

Revista LiminaR. Estudios sociales y humanísticos, año 7, vol. VII, núm. 1, junio de 2009, Tuxtla Gutiérrez, Chiapas, México. ISSN: 1665-8027 
los que se podía acceder para que atendieran peticiones de los hombres. Estos animales fueron frecuentemente reproducidos en pinturas precolombinas. Las deidades que desempeñan el papel más importante en la mitología ch'ortí son los chicchanes (serpientes sobrenaturales), y las hay de dos tipos: del cielo y de la tierra. Los que proceden del cielo producen la lluvia y los fenómenos celestes; en cambio, los terrestres son responsables de las inundaciones, tormentas y movimientos telúricos. En otras palabras, se puede decir que los chicchanes (Hor chan) son los causantes del beneficio o perjuicio para la humanidad.

Para Girard y Wisdom, el chij chan o chicchan ${ }^{9}$ es una serpiente de gran tamaño y su cuerpo tiene variaciones. En algunos casos "la mitad superior del cuerpo es de humano, mientras que el resto o la parte inferior podría representarse como una serpiente emplumada". Otras veces se describe como "una sierpe con cuernos en la cabeza" o bien, como "un animal terrestre que tiene la potestad de subir al cielo durante la temporada de lluvia y luego regresa a su morada terrenal, no obstante, aunque tiene potestades de abrir el cielo, no se le puede considerar celeste" (Girard, 1949 TII: 578,579; Wisdom, 1961: 444). Los chubascos y las tormentas son causados por el paso veloz de un chicchan y respecto al arcoíris hay dos versiones: es el cuerpo de un chicchan extendido en el cielo, y el resuello del chicchan después de la tormenta. El trueno es el grito de un chicchan que se comunica con sus compañeros que están del otro lado del firmamento y sus respuestas producen truenos continuos. Todos los seres sobrenaturales poseen neutralidad, dualidad moral, dualidad sexual, multiplicidad y bilocalidad (en el cielo y en la tierra) (Wisdom, 1961: 444).

Hor chan es una serpiente gigantesca. Aunque con numerosas variaciones de forma, es la más importante de la deidades nativas de la región ch'orti'. Los ancianos cuentan que en su cabeza tiene uno o varios cuernos con brillo de oro y, en la cola, cascabeles.

En el Popol Vuh (Recinos, 1974: 25), antiguo manuscribo de los K 'iche', se relata “...en la oscuridad de la noche, los progenitores, Tepeu, Gucumatz, estaban en el agua, en la oscuridad, en la noche, hablaron entre sí, se pusieron de acuerdo...que cuando amaneciera debía aparecer el hombre". En la llamada de atención del preámbulo, Recinos (1974: 159) dice: "que los Quichés asociaban el nombre Gucumátz con el elemento líquido". El Obispo Núñez de la Vega dice, que "Gucumatz es culebra de plumas que anda en el agua". El manuscrito Kakchiquel (Memorial de Sololá/Anales de los Kaqchikeles, Recinos, 1981), refiere que a uno de los pueblos primitivos que emigraron a Guatemala "se le llamó Gucumatz, porque su salvación estaba en el agua”.

De estos antiguos textos se puede observar alguna relación con la mitología ch'orti'. Los chicchanes de la tierra son los que producen los fenómenos terrestres, por ejemplo, son los causantes de las inundaciones. Esto ocurre cuando luego de la tormenta enviada por los chicchanes del cielo, los chiccchanes de la tierra recorren los causes de los ríos y provocan que los mismos se desborden y haya destrucción de todo lo que encuentran a su paso. Los terremotos, deslaves o derrumbes son causados por movimientos de los chicchanes en el interior de las colinas.

Respecto a estas creencias en tiempos más recientes, se puede leer en la Monografía de San Juan Ermita -uno de los municipios de Chiquimula- (Jordán, 1998: 34), lo siguiente:

...en el interior del cerrón, se encuentra la imagen de San Juan Bautista, quien con una cadena de oro amarrada en el dedo meñique de una de sus manos, sostiene una enorme serpiente, la cual es encantada. El día que San Juan Bautista la suelte, se pierde el pueblo...otros consideran que la serpiente es la que está deteniendo toda el agua que se extiende dentro del cerro y si San Juan Bautista la suelta, el pueblo se inunda.

Esto quiere decir que aun en tiempos coloniales, cuando se introdujo esta imagen a la región ch'orti' y hasta la ac- 
tualidad, las serpientes siguen jugando un papel importante en la cosmovisión de la comunidad para establecer los ciclos de lluvia y sequía y se les sigue considerando las responsables de los movimientos telúricos.

En Mesoamérica, las representaciones de serpientes abundan en códices pictóricos, esculturas, murales y en topónimos. La serpiente es representada en relación con la tierra, el agua y los poderes fecundadores. Fray Andrés de Olmos, también describe a la serpiente en su texto colonial Arte para aprender la lengua mexicana; dice: "cubre todo lo que abarca. Propicia el crecimiento, el reverdecimiento. Su plumaje es iridiscente". Es por ello que la serpiente se relaciona tanto con el cielo como con el agua de lluvia y con el agua estancada.

Finalmente es importante destacar que para Girard hay tres datos importantes concernientes a la serpiente en el área maya ch'orti'. El primero es la cruz de alto simbolismo en esta zona, formada por el entrecruzamiento de cuatro sierpes (serpientes); el segundo es el número de bandas escalonadas o en grecas en cualquier representación relacionada con una nube serpentina; el tercero, se refiere al antiguo traje de las mujeres (hoy caído en desuso), el cual estaba decorado con figuras del cosmos (la luna, patrona de las mujeres ch'orti', aparece de forma emblemática de U y con entrecruzamiento de líneas serpentinas en el cuello de la blusa) (Girard, 1949 T.I: 277; Girard, 1949 T.II: 573).

\section{Rito para la serpiente entre los ch'orti'; otras costumbresy creencias relacionadas}

La ceremonia dedicada a la serpiente está vinculada al ciclo agrícola y a la invocación de la lluvia, por lo que una parte de la misma la debe realizar en forma secreta un chamán llamado el padrino y también Hor chan o Jor chan. Los padrinos - por lo general ancianos líderesson los únicos que pueden desempeñar las principales funciones rituales en el interior de la comunidad, en sus ceremonias nativas. Estas funciones son la de Mayordomo de la cofradía, a cargo del santo patrón del poblado; y la de Hacedor de Lluvia (Tax, 1964: 282; Wisdom, 1961: 373, Girard, 1949).

Para los ch'orti', los lugares sagrados son áreas geográficas en los que habitan los seres sobrenaturales, entre ellos, los chicchanes. También son sagrados los sitios en donde se llevan a cabo ceremonias rituales. Estos espacios lo constituyen todas las fuentes de agua (como aguas termales — también son lugares medicinales-, ríos, arroyos, lagos, lagunas), colinas y cuevas (Wisdom, 1961: 478, 479).

Respecto a la cruz que se relaciona con cuatro serpientes cruzadas, Girard identifica el mismo número de reptiles que viven en las lagunas localizadas en Coatepeque, Golfo Dulce, Ipala y el Sillón (Girard, 1949: 574).

Wisdom (1961: 494) observó directamente el ritual para la serpiente, mismo que tenía el propósito de pedir la llegada de la lluvia. Sus escritos indican que la ceremonia principal se llevaba a cabo el 25 de abril de cada año. Durante este ritual se presentaban como ofrendas sagradas maíz, pavos y copal. El ritual tiene dos partes. La primera se lleva a cabo muy temprano en la mañana alrededor de la casa ritual, "el padrino excava 4 agujeros en las esquinas de la casa ceremonial y entierra en cada esquinero un guacal de chilate...". La segunda parte se efectúa fuera de la casa, en un lugar sagrado en el campo. En este momento, "todos se dirigen con el padrino al pie de cualquier colina o la fuente sagrada, hogar de chicchan". Sobre los objetos de ofrenda, Wisdom indica que

el maíz nunca se ofreció en estado crudo, sino cocido en alguna forma, ya sea como atole o chilate; los pavos hembra y macho, eran sacrificados sin preparación culinaria, ofreciendo la sangre junto con la carne...El copal después de haber sido modelado en forma de pesos de plata (tostones) o de panecillos, es enterrado o quemado en los incensarios familiares... (Wisdom, 1961: 491) 
Wisdom anotó que las ofrendas tienen el único propósito de pagar a la deidad a cambio de que se concediera lo pedido en las oraciones del ritual. En el lugar donde se lleva a cabo la segunda parte del ritual, es decir en el campo, en las fuentes de agua o las colinas, el dirigente o padrino cava un agujero en el suelo y derrama la sangre del pavo y la pava para, posteriormente, lanzar el cuerpo de los animales dentro del agujero. Siempre se tenía el cuidado de que el macho quedara enterrado del lado de la fuente de agua o de la colina y la hembra en el lado opuesto. En el centro, es decir, entre las dos aves se arrojaban piezas de copal modeladas. Luego debía cubrir el agujero para que los hechiceros no lo descubrieran y se hacía una plegaria a las deidades que producen el agua, a los chicchanes, quienes agitan el agua de los ríos, lagos, lagunas y del mar. También se debía rogar a los dioses del viento, portadores de la lluvia por toda la tierra; y al dios de la tierra, por la fertilidad. Esta plegaria se ofrecía directamente a Dios para que diera permiso a sus ministros para que enviaran la lluvia y, además, para que la evaporara en su justa medida, evitando desgracias (Wisdom, 1961: 495).

Debido a que son seres con habilidades especiales, durante este tiempo ritual el padrino y sus ayudantes (personas que lo asisten ocho días previos y posteriores a la ceremonia), deben tener una dieta de purificación que consiste en comidas a base de maíz, esencialmente del tipo de atol llamado chilate (Wisdom, 1961: 490).

El común de los ch'orti' también consumía alimentos especiales durante sus festividades rituales, tales como tamales, tortillas, atole, chilate y cacao, pero la bebida principal era la chicha (bebida fermentada de maíz), ya que después del ritual todos se emborrachaban, excepto los niños (Wisdom, 1961: 492).

Más recientemente, el antropólogo Celso Lara registró un dato interesante en la aldea Marimba, Camotán. El mismo indica que los ancianos suben al cerro Moujá para pedir al Dueño de éste que les mande lluvia. Este Señor es una gran culebra a la que debe pagársele con costumbre (ritos), maíz y cacao.

Cabe afirmar que actualmente todavía existen informantes ancianos en la zona ch'orti' y en el municipio de Chiquimula que explican el mismo ritual observado por Wisdom. Éste era practicado durante la juventud o infancia de los informantes, sea por ellos mismos, actuando como padrinos; o por familiares cercanos.

Hay también otras consideraciones importantes en los textos de Girard y Wisdom que hablan de la cosmovisión ch'orti' y de cómo ésta se relaciona con la serpiente representada en el sitio Los Migueles. Girard, indica que los ch'orti' poseían amplios conocimientos astronómicos (equinoccios, solsticios, travesía del sol a través del cenit, ciclos lunares y movimiento de las estrellas), íntimamente ligados a su vida cotidiana, trabajo y cosmovisión. En uno de los casos citados por Girard, uno de los padrinos de la comunidad de Santa Rosalía, Esquipulas, le mostró los puntos específicos en el horizonte de la localidad, usados en ese entonces para determinar la travesía del sol a lo largo de las estaciones. Tomado de Girard (1949 T.II: 438), se puede leer lo siguiente:

El sacerdote... tiene marcados 'sus puntos' en la línea oriental, desde la Pena de Cayaguanca, donde está el punto de referencia del solsticio de invierno, hasta el Cerro Redondo del Cocal, que señala la llegada del astro al solsticio vernal, en la cadena montañosa del Merendón; pudiendo indicar con exactitud, en los relieves topográficos a lo largo de esta línea básica, los diferentes 'puestos' correspondientes a la posición solar en las fechas siguientes: ocho de febrero, cuando el astro-dios se dispone a dejar su ocio divino para emprender la marcha hacia el rumbo opuesto, buscando 'la medianía del mundo' o la línea del paralelo; el día en que toca el punta equinoccial; el día del paso por el paralelo del lugar; el día del solsticio de verano. Idéntico registro se encuentra en la línea occidental del 
HOR CHA'AN: LA SERPIENTE MíTICA CH'ORTÍ EN EL ARTE Rupestre de Chiquimula, Guatemala

horizonte, donde los cerros Tichaku y las Moras, señalan respectivamente los extremos solsticiales... (Girard, 1949 T.II: 438).

Por otra parte, también el sacerdote de Tan Sha usaba el paisaje con el mismo propósito; su horizonte estaba configurado por la sierra del Merendón y los cerros de las localidades de Cayur, Camotán, Quezaltepeque y Esquipulas (Girard, 1949 T.II: 439, 441, 443, 444). En nuestros días, la etnografía indica que el paisaje (cerros, montes, cuevas y montanas) de la región ch'orti' todavía juega un papel activo en la actividad ritual y cosmogónica de la Hor Chan.

Datos adicionales e interesantes se encuentran en ciertos rituales de migración entre el este y el oeste para atraer a las lluvias hacia la región ch'orti'. Wisdom (1961: 413-414) reporta que los chó ortí de Camotán (localizado al Este) acuden a la población de Jocotán (localizado en el Oeste) y llevan a un santo de esta localidad en procesión (San Antonio, según Lara) para que favorezca las lluvias.

En los rituales de lluvia de la localidad de Quezaltepeque, Girard (1949 T.II: 413) también registró que durante el 14 de enero los pobladores hacían un viaje ritual hacia el Este para traer el invierno; mientras que el 8 de febrero se realiza el viaje hacia el Oeste, en sentido contrario, para simbolizar el fin del invierno. Según Girard (1949 T.II: 413), este viaje entre Este-Oeste representa el ciclo diario de la travesía del sol.

Es importante hacer notar que en la actualidad, el Cristo Negro de Esquipulas, tiene dos días ceremoniales en el año. El primero, realizado el 15 de enero, está dedicado a la imagen y a la fecha en que se esculpió; el segundo, celebrado el 9 de marzo, se relaciona con el traslado de la imagen a la nueva Basílica. Debido a la coincidencia de estas fechas de celebración religiosa en Esquipulas se puede inter pretar que tanto la de Camotán, como las de Quetzaltepeque y Esquipulas tienen que ver con antiguas costumbres prehispánicas que servirán para atraer y alejar la lluvia, y que eran representadas mediante viajes entre el Este y el Oeste.

Según Lara, en Camotán se cree que la cruz del Señor de Esquipulas está asentada sobre un pozo de agua milagrosa que da a una cueva donde habitan los dioses de Xibalbá. Sin embargo, el ingreso a esta cueva únicamente es conocida por los sacerdotes de Esquipulas y los ancianos-rezadores de Camotán.

\section{Discusión}

Los elementos teóricos presentados en este trabajo ayudan a proporcionar una explicación para la representación rupestre de la serpiente plasmada en el peñasco Los Migueles, San Juan Ermita, Chiquimula. La complejidad de las tradiciones orales (etnografía) del grupo ch'orti' que habita en las cercanías, los elementos de su idioma, el análisis del paisaje circundante y la información encontrada en fuentes etnohistóricas del período Posclásico son elementos que permiten identificar dicha pintura rupestre como la principal deidad prehispánica de la zona.

En su aspecto morfológico y tal como lo indican las creencias sobrenaturales de los ch'orti', la pintura de Los Migueles posee cuernos en la cabeza, de la misma forma que la serpiente mítica Hor chan o, simplemente, chicchan. Su cuerpo almenado denota movimiento, ya sea como el agua de un río; o al desplazarse - en su connotación terrestre- de un lugar a otro, entre los montes o en los valles. En este sentido, también la dirección (Este-Oeste) en que fue pintada coincide con el curso natural del río Carcaj, principal fuente de agua de la zona que corre en el valle, dos kilómetros al sur del abrigo rocoso.

Para los pobladores ch'orti' hay varias creencias importantes en cuanto a la serpiente mítica. Se sabe que un reptil de gran tamaño habita las montañas. Es tan grande que la cabeza se ubica en el cerro llamado Churischán, en San Juan Ermita; mientras que la cola está en el de Nochán, Olopa, dos municipios de 
Chiquimula separados por más de siete kilómetros. El primero se localiza al este del segundo, lo que refuerza nuevamente la importancia de que la cabeza del ofidio siempre se encuentre hacia la salida del sol. Actualmente, el nombres de ambos cerros en ch'orti', se interpretan como "lugar de la serpiente". Según el diccionario de Wisdom (1950), "ch'uri's ch'a'n es el nombre de una colina cerca de Camotán, en la que se dice vive un chicchan, protector del pueblo de Camotán". Noh chan simplemente significa chicchan, "deidad serpiente del agua y la lluvia".

En cuanto a las expresiones idiomáticas que se relacionan con serpiente, los términos Hor chan, chichchan o chan son elementos con fuerte connotación polisémica. Hor chan es el nombre propio de la serpiente, pero también se identifica con el personaje ritual más importante de la zona, el padrino o hacedor de agua. Para Wisdom muchas de las palabras en ch'orti' con las que está relacionado el término chan, involucran los verbos mover, retorcer y contraer; o bien connotan sustantivos (nombres de cosas, órganos, padecimientos) que asocian la idea de una serpiente. Chan es, "serpiente, lombriz grande, intestino, esófago, línea zigzagueante, línea curveada, recodo, contracción muscular y cólico".

Dado que en la región son abundantes las cuevas, las montañas escarpadas y las grandes formaciones rocosas, los ch'orti' asocian la topografía exterior - montañas y abrigos-, e interior - cuevas-, con un paisaje zigzagueante resultado de los desplazamientos que un chichchan hace a través de la región. Además, los sismos (falla de Jocotán) o los derrumbes se atribuyen a períodos en los que la serpiente gigante se encuentra inquieta entre los cerros o en el fondo de los valles. Al igual que el fenómeno de la contracción (o chan, expansión de una serpiente), el agua a través de su desplazamiento en los meandros del los ríos, contrae y expande el paisaje.

Cuando ocurre un sismo producto del movimiento de la serpiente al desplazarse en el interior de la tierra también ocurre una contracción de las fuentes de agua y de las lluvias. La carencia de agua puede tener resultados catastróficos. Para evitar esto hay que rogar a la mayor de las serpiente, Hor chan, quien en realidad habita en el cielo o en otro plano sobrenatural. El ritual y las ceremonias son críticos para prevención tanto de sequías como de inundaciones.

Según las fuentes etnohistóricas, en su connotación más benevolente las serpientes míticas se relacionan con el proceso de la lluvia y, por tanto, de la fecundidad de la tierra. De acuerdo al ritual explicado por Wisdom hay varias partes del ritual llevado a cabo por el padrino como hacedor de lluvia: la primera consiste en ofrendas (sangre y copal) a la tierra y al dueño de la tierra (una serpiente o chicchan); la segunda, en ruegos a los señores de los vientos para que limpien el cielo y permitan aproximarse la lluvia; la tercera, en oraciones al señor del agua y la fecundidad. Al tener la cabeza mirando hacia el este, la serpiente rupestre pintada en el peñasco Los Migueles se relaciona con la salida del sol donde está el origen de la vida y la fecundidad en la cosmovisión prehispánica mesoamericana.

\section{Conclusión}

Las consecuencias de los fenómenos climáticos y telúricos han sido discutidas a partir de las evidencias arqueológicas y paleoclimáticas con el propósito de explicar el "colapso" y el estrés social ocasionado por estos fenómenos en las poblaciones mayas del período Posclásico (Curtis et al., 1996; Hodell et al., 1995; Hodell et al., 2001; Folan et al., 1983; Gunn et al., 1995; Gunn et al., 2002). Desde la perspectiva particular del arte rupestre de la región ch'orti', Hor chan es un símbolo ritual, una metáfora que denota la conceptualización cultural de la forma escarpada de los cerros, las cuevas, las manifestaciones hídricas y los movimientos telúricos. Es decir, la sierpe (Hor chan o chicchan) fusiona simbólicamente el paisaje externo e interno de la región ch'orti' y el estrés social causado por el afán de procurarse el recurso hídrico mediante rituales y las representaciones rupestres de la serpiente en un lugar sagrado donde seguramente 
también se llevaron a cabo ceremonias en tiempos prehispánicos. El éxito de los mismos, procurado por un personaje ritual, ha asegurado el equilibrio del mundo ch'orti', así como la vida y la fertilidad de los valles.

\section{Notas}

' Significante: Plano de expresión del signo; sustancia material del signo o la manera de poder manifestarse (López, 1994: 34-35, citando a Barthes, 1972 e Interiano, 1991).

2 Significado: Plano de contenido del signo; idea inmediata que se refiere al significante o mensaje sugerido por la forma material (López, 1994: 34-35, citando a Barthes, 1972 e Interiano, 1991).

${ }^{3}$ Geertz (1973) define visón del mundo como una conceptualización de la totalidad en que se conoce los aspectos existenciales de la naturaleza y la sociedad.

${ }^{4}$ Identidad étnica también es entendida como intereses y necesidades de un grupo (Hodder ,1979: 452).

${ }^{5}$ Los sitios marcados con itálica, se localizan fuera de la zona ocupada por la etnia ch'orti'.

${ }^{6}$ Se cree que pudo ser más larga, ya que la pintura -en la parte final del cuerpo- ha cedido a las condiciones ambientales y al tiempo. También hay representaciones de serpientes, más naturalistas, en el sitio Chatún de la Rebalsa, en la aldea Shupá, Camotán y en el peñasco Alonzo, San Juan Ermita.

${ }^{7}$ La cabeza mira hacia el este, lugar donde sale el sol. En la cosmovisión mesoamericana, este acto, asegura la continuidad de la vida.

${ }^{8}$ Charles Wisdom de la Universidad de Chicago, trabajó en la zona ch'orti" hacia los 1910; The Chorti Indians of Guatemala, es el producto de su investigación. A mitad del siglo XX, Rafael Girard hace una investigación similar en el área con propuestas arqueológicas interesantes. Su obra en este ámbito es Los Chortis ante el problema Maya: Historia de las culturas indígenas de América desde su origen hastahoy.

${ }_{9}^{9}$ Respectivamente, estos autores escriben el nombre de estos seres míticos con redacción diferente.

\section{Bibliografía}

Aguilera, Carmen (1985), Flora y Fauna Mexicana, México: Mitología y Tradiciones, Everest.

Alcina Franch, José (1982), Arte y Antropología, México: Alianza.

Barthes, Roland (1972), La Semiología, Buenos Aires: Tiempo Contemporáneo.

Batres, Carlos et. Al. (1999), Informe final de temporada 1998, Proyecto Arqueológico Estudio de la pintura rupestre de Chiquimula, Guatemala: Escuela de Historia, Universidad de San Carlos de Guatemala.

Bradley, R. (1997), "Working the land: imagining the landscape", en Archaeological Dialogues, vol. 4. Núm. 1, pp. 39-48, Cambridge: Cambridge University Press.

Christentson, Allen J. (1985), K'iché-English Dictionary and Guide to pronunciation of the K'iche'Maya alphabet, USA: Brigham Young University, FAMSI.

Curtis, Jason H. et. al. (1996), "Climate variability on the Yucatan Peninsula (Mexico) during the last 3500 years and implications for Maya cultural evolution", en Quaternary Research, vol. 46, pp. 37-47.

Eco, Umberto (1976), Tratado de semiótica general, Lumen, Barcelona.

England, Nora (1999), "Reconstrucción y características de los idiomas prehispánicos de Guatemala”, en Marion de Hatch (directora de tomo), Historia General de Guatemala, vol. 1, Guatemala: Asociación de Amigos del País, Fundación para la Cultura y el Desarrollo, pp. 641-650.

Folan, W. J. et. al. (1983), "Paleoclimatological Patterning in Southern Mesoamerica", en Journal of Field Archaeology, 10, pp. 454-468.

Gamboa, Luis (1996), "La serpiente en el mundo prehispánico”, en Actualidades Arqueológicas, núm. 06, México, pp. 3-4.

Geertz, Clifford (1973), The Interpretation of Cultures, New York: Basic Books. 
Girard, Rafael (1949), Los Chortis ante el problema Maya: Historia de las culturas indígenas de América desde su origen hasta hoy, 6 Tomos, México: Antigua Librería Robredo de José Porrúa e hijos.

Gunn, J.D., W.J. Folan y H.R. Robichaux (1995), “A landscape analysis of the Candelaria watershed in Mexico: insights into plaeoclimates affecting upland horticulture in the southern Yucatan Peninsula semi-karst", en Geoarchaeology, núm 10, pp. 3-42.

Gunn, Joel D. et. al. (2002), "Climate-change studies in the Maya area", en Ancient Mesoamerica no. 13, USA: Cambridge University Press, pp.79-84.

Hodell, David A. et. al. (1995), "Possible role of climate in the collapse of Classic Maya civilization", en $\mathrm{Na}$ ture, núm. 375, pp. 391-394.

Hodell, David A. et. al. (2001), "Solar forcing of drought frequency in the Maya lowlands", en Science, núm. 292, pp. 1367-1370.

Hodder, Ian (1979), "Social and Economic Stress and Material Culture Patterning", en American Antiquity, vol. 44, pp. 446-454.

Hull, Kerry (2005), An abreviated dictionary of Ch'orti Maya, USA: FAMSI.

Interiano, Carlos (1991), Semiología y comunicación, Guatemala: Ed. Fénix

Jordán, Milton (1998), San Juan Ermita. Monografía, Guatemala.

López, Fredy (1994), La iconografía en la danza ancestral de Cunén, Quiché, Tesis de licenciatura, Guatemala: Escuela de Ciencias de la Comunicación, Universidad de San Carlos de Guatemala.

Pérez-Castro, Guillermo (1996), "Algunos comentarios acerca de la cabeza de serpiente descubierta en la casa de la primera imprenta en América. Lic. Verdad y moneda núm.10", en Actualidades Arqueológicas, núm. 06, México, pp. 3-4.
Rapoport, A. (1992), "On Cultural Landscapes", en Traditional Dwellings and Settlements Review, vol. 3, núm.11, pp. 33-47.

Recinos, Adrián (1974), El Popol Vuh: las antiguas historias del quichép, Guatemala: Ed. Universitaria Centroamericana.

Recinos, Adrián (1981), Memorial de Sololá/Anales de los Kaqchikeles/Título de los Señores de Totonicapán, Guatemala: Ed. Piedra Santa.

Rice, Prudence (1983), "Serpents and Styles in Peten Postclassic Pottery", en American Anthropologist, núm. 85, pp. 866-880.

Sahagún, Bernardino (2006), Ángel Ma. Garibay (ed.) Historia General de las Cosas de Nueva España, México: Porrúa.

Tax, Sol (1964), "Cultural differences in the Maya area: a 20th century perspective", en Evon Z. Vogt y Alberto Ruz L. (eds.), Desarrollo cultural de los Mayas, México: UNAM.

Viramontes, Carlos (1999), "Las manifestaciones gráficas rupestres. Una búsqueda metodológica", en Carlos Viramontes y Ana María Crespo (coords.), Expresión y Memoria. Pintura rupestre y petrograbados en las sociedades del norte de México, México: INAH, pp. 27-42.

Whitley, David (1998), "Finding rain in the desert: landscape, gender, and far western North America rock art", en C. Chippindale y P.S.C. Taçon (eds.), The archaeology of rock art, Cambridge: Cambridge University Press, pp. 11-29.

Whitley, David (2005), Introduction to Rock Art Research, California: Left Coast Press.

Wisdom, Charles (1950), Chorti Dictionary, Chicago: Ed. Brian Stross.

Wisdom, Charles (1961), Compilación documental los Chortís de Guatemala, Guatemala: Ed. José Pineda Ibarra. 


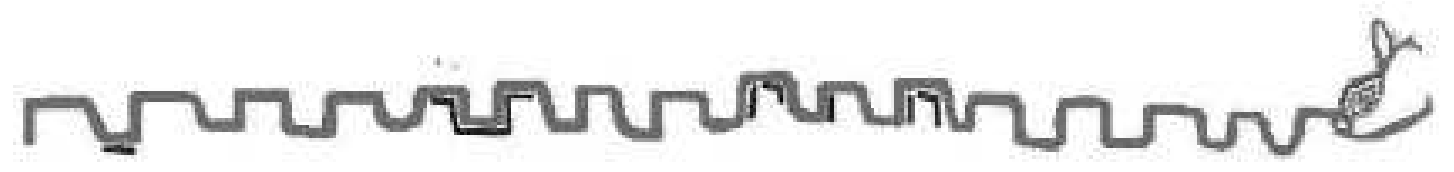

Figura No. 1

Calco de la Serpiente Almenada, Peñasco Los Migueles. Se propone que es la representación de la serpiente mítica Hor Chan (los detalles en negro representan el trazo en negro ya desvanecido por acción del tiempo; el resto de la pintura está plasmada en rojo) (Proyecto Arqueológico Estudio de la Pintura Rupestre de Chiquimula).

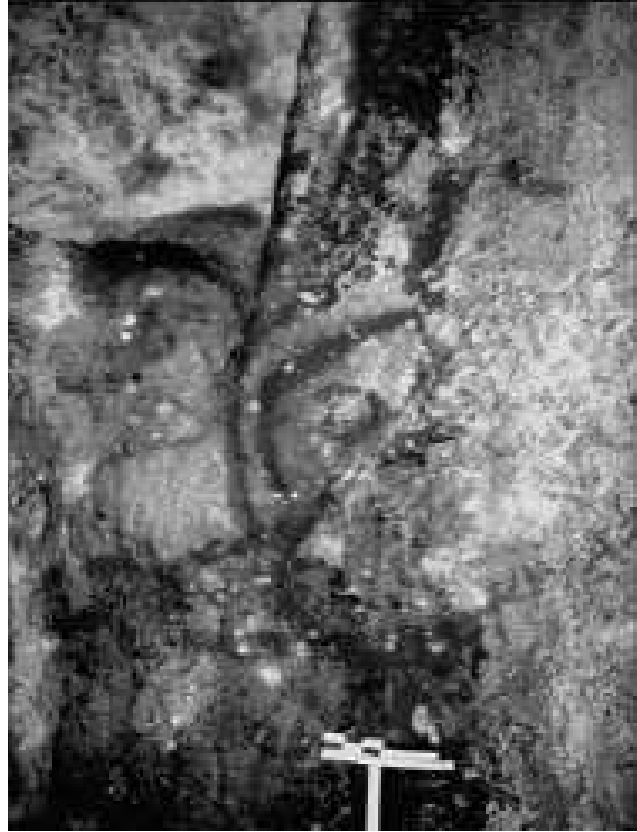

Figura No. 2

Detalle de la cabeza de la Serpiente Almenada, Peñasco Los Migueles

(Fotografía de Proyecto Arqueológico Chiquimula).

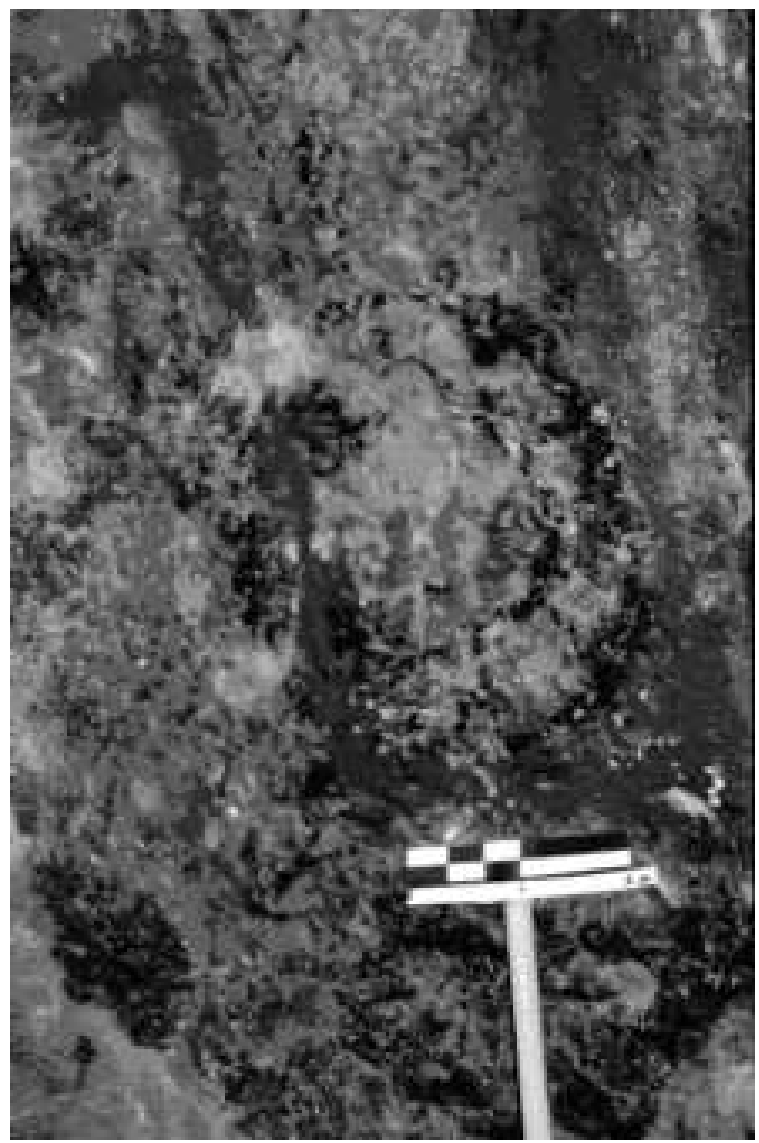

Figura No. 3

Detalle de una de las almenas de la pintura de la serpiente, Peñasco Los Migueles (la almena está sobrepuesta a la representación de otro elemento, probablemente una planta alucinógena) (Fotografía Proyecto Arqueológico Chiquimula). 


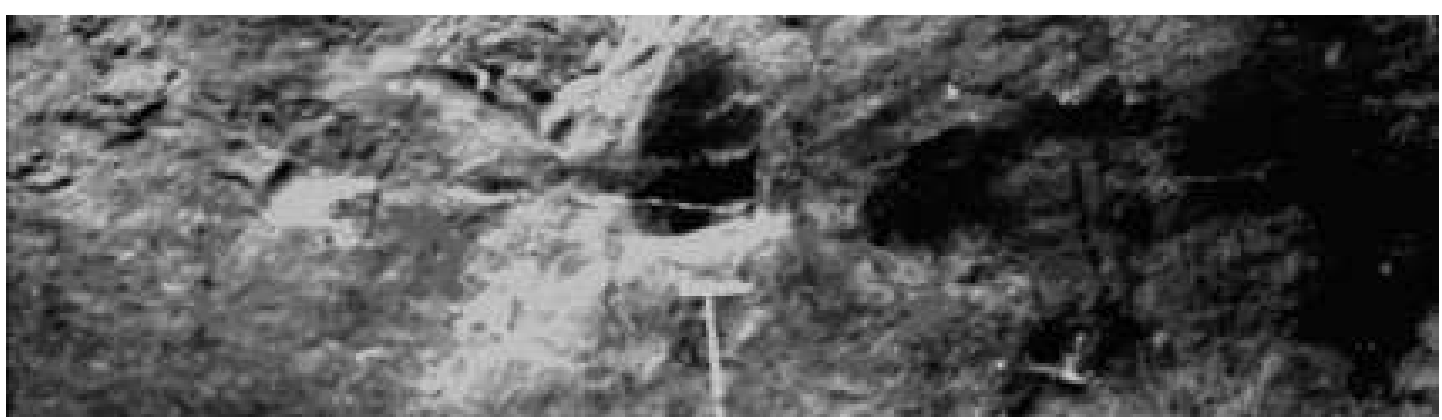

Figura No. 4

Detalle de cuerpo almenado de la serpiente del Peñasco Los Migueles (las almenas están sobrepuestas a la representación de un mamífero, probablemente un jaguar, pintado en negro a la derecha) (Fotografía Proyecto Arqueológico Chiquimula)(Fotografía Proyecto Arqueológico Chiquimula).

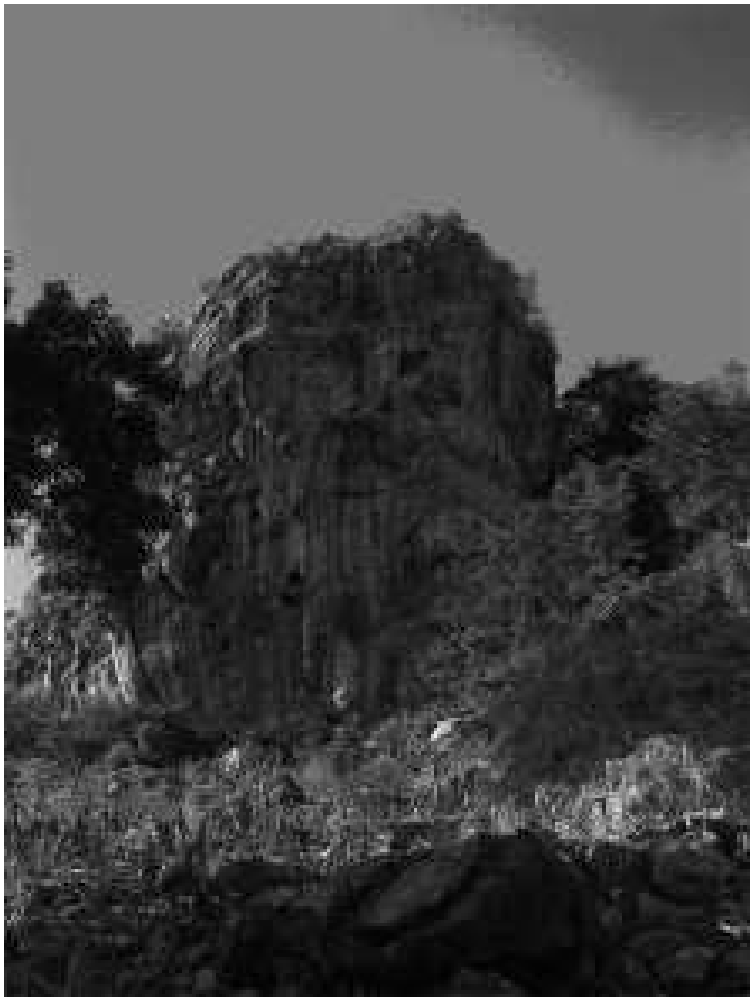

Figura No. 5

Vista frontal del sitio rupestre Peñasco Los Migueles donde fue plasmada la serpiente almenada (Fotografía de Proyecto Arqueológico Chiquimula).

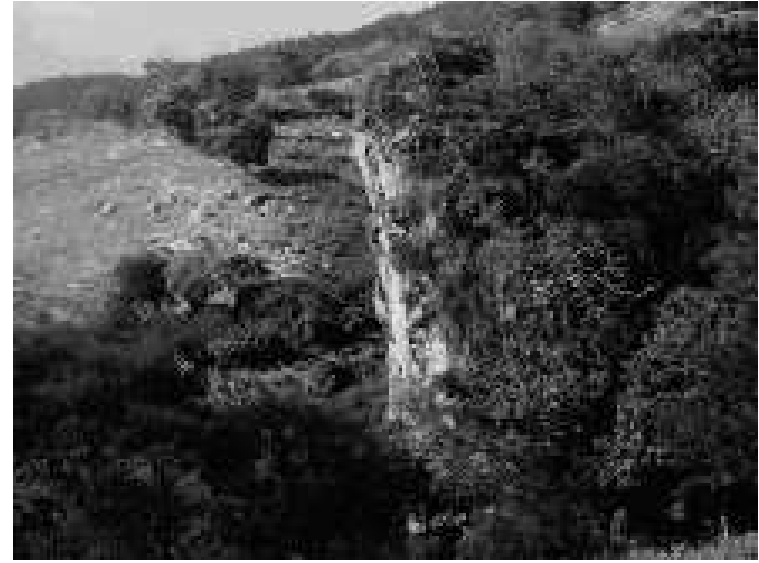

Figura No. 6

Vista desde la parte superior del Peñasco Los Migueles (Fotografía de Proyecto Arqueológico Chiquimula). 
HOR CHÁ AN: LA SERPIENTE MÍTICA CH'ORTÍ EN EL ARTE Rupestre de Chiquimula, Guatemala

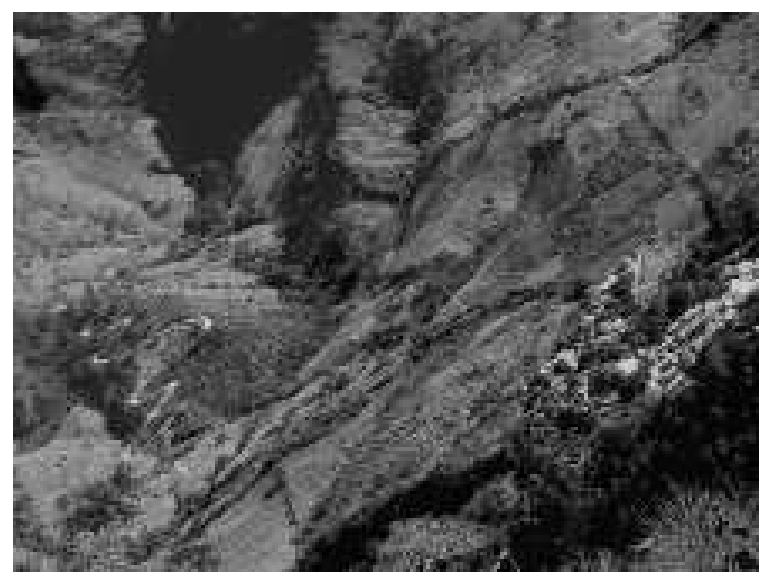

Figura No. 7

Paisaje del área $\mathrm{Ch}^{\circ}{ }^{\circ}$ rti $^{\prime}$, dominado por montañas, escarpas y formaciones rocosas

(Fotografía de Proyecto Arqueológico Chiquimula)

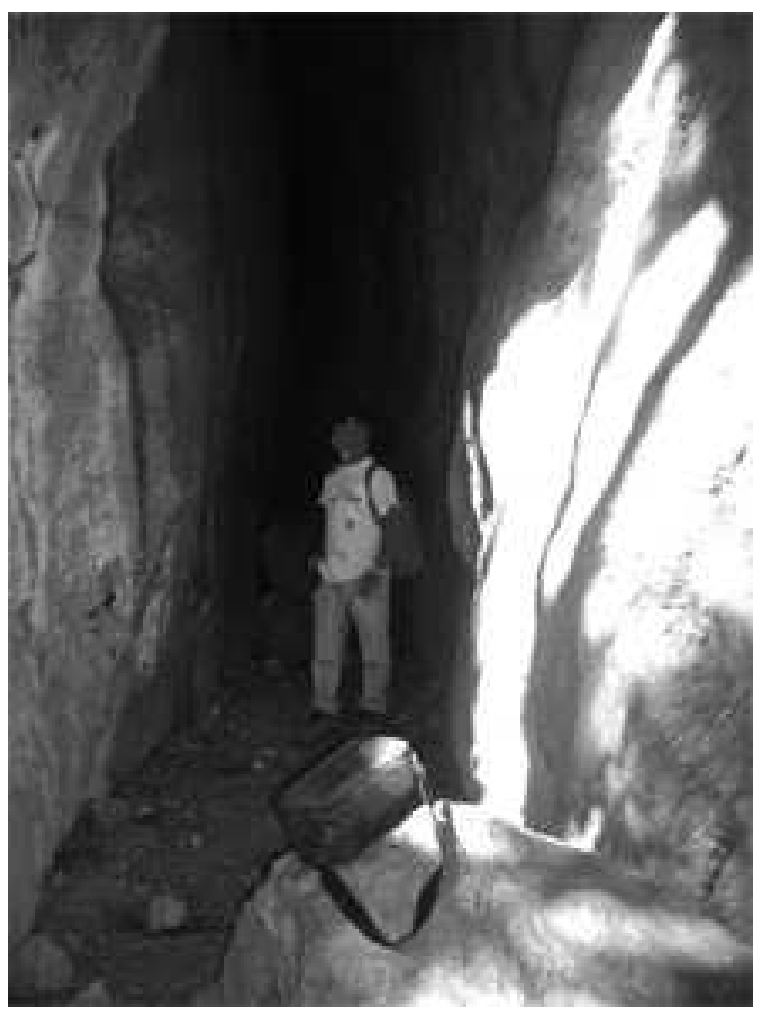

Figura No. 8

Entrada a la cueva Helada, alrededores del Peñasco Los Migueles (Fotografía de Proyecto Arqueológico Chiquimula) 